\title{
Entre afinidades eletivas e escolhas pragmáticas
}

$\mathbf{N}$ Ão são simples as relações das ciências sociais com os seus clássicos, e no caso das ciências sociais praticadas no Brasil o dissenso é especialmente agudo quanto à tradição intelectual anterior à sua institucionalização como disciplina acadêmica identificada como "pensamento" social e político. Malgrado seu expressivo crescimento nas últimas décadas, o significado da pesquisa dessa tradição para a busca contemporânea de conhecimento continua em aberto, não sendo incomuns visões segundo as quais as ciências sociais já deveriam ter solucionado as questões colocadas pelas interpretações mais antigas. Estamos, é claro, num dos campos de disputa pela própria definição da identidade cognitiva da disciplina. Nenhuma surpresa, pois, que certos exageros quanto à distância que nos separaria de nossos predecessores sejam cometidos, afinal, como há muito se sabe, essa é uma das estratégias mais eficientes e recorrentes sempre que uma "nova geração" busca afirmar-se.

Estudando o fenômeno relativamente à reação dos jovens naturalistas ao romantismo, Machado de Assis já aconselhava a procurar divisar na "chasqueia" a inevitável continuidade, posto que nem mesmo "a extinção de um grande movimento literário não importa a condenação formal e absoluta de tudo o que ele afirmou; alguma coisa entra e fica de pecúlio do espírito humano" (Assis, 1962, p.810). A ponderação realista de que continuidades e rupturas absolutas só são possíveis mesmo no plano da me- tafísica não parece ter sido muito acatada entre nós; afinal, prevalece ainda a impressão - nem sempre ingênua - de que nossa vida intelectual esteja sempre recomeçando do zero a cada nova geração (Schwarz, 1987).

Como se tivesse ouvido o conselho machadiano, Linhagens do pensamento político brasileiro de Gildo Marçal Brandão persegue o fio que nos tem ligado na prática das ciências sociais, e nas suas formas correspondentes de pensar o Brasil e nele atuar, ao nosso passado intelectual, e desafiadoramente nos mostra que, também nesse caso, os fios mais finos podem mesmo ser os mais firmes. ${ }^{1}$ Trata-se de um programa de pesquisa consistente que, explorando a fundo as conseqüências do fato de que nenhuma inovação intelectual se realiza num vazio cognitivo, propõe nova inteligibilidade para o pensamento político-social brasileiro. Mais do que mera testemunha do passado, esse constituiria o índice da existência de um corpo de problemas e soluções intelectuais - "um estoque teórico e metodológico" - a que autores de diferentes épocas são levados a se referir, ainda que indiretamente e guardadas as especificidades cognitivas e políticas de cada um, no enfrentamento de velhas questões postas pelo desenvolvimento social. Não se trata de minimizar o influxo cognitivo externo a que também as ciências sociais brasileiras estão sujeitas em sua prática cotidiana, e sim de reconhecer que, ainda assim, o pensamento político-social brasileiro tem representa- 
do "um afiado instrumento de regulação de nosso 'mercado interno das idéias' em suas trocas com o mercado mundial" (p.23-4).

A hipótese geral do livro apresentada em seu primeiro capítulo é que os conceitos de "idealismo orgânico" e "idealismo constitucional" formulados por Oliveira Vianna possuem valor cognitivo heurístico para repensar a tradição intelectual brasileira do Império aos nossos dias, embora esses conceitos estejam referidos especialmente às relações entre Estado e sociedade. Assim, cotejando diferentes trabalhos e autores contemporâneos e do passado recente ou mais remoto, Brandão situa o liberalismo atual numa linha de continuidade que se inicia com a sugestão de Tavares Bastos sobre o caráter parasitário do Estado brasileiro, passa pela tese de Raymundo Faoro sobre a permanência de um estamento burocrático-patrimonial e chega à proposta de Simon Schwartzman e outros “americanistas" de “(des)construção de um Estado que rompa com sua tradição 'ibérica' e imponha o predomínio do mercado, ou da sociedade civil, e dos mecanismos de representação sobre os de cooptação, populismo e "delegação" (p.33-4). Do mesmo modo seria possível surpreender a atualização da crítica saquarema ao suposto utopismo dos liberais, malgrado seus sentidos distintos, nos trabalhos do visconde do Uruguai, do próprio Oliveira Vianna, de Guerreiro Ramos ou Wanderley Guilherme dos Santos, entre outros. Os dois capítulos seguintes, o segundo e o terceiro, são dedicados à investigação do programa de pesquisa conservador e algumas de suas atualizações nas análises de, respectivamente, Oliveira Vianna e Oliveiros S. Ferreira.

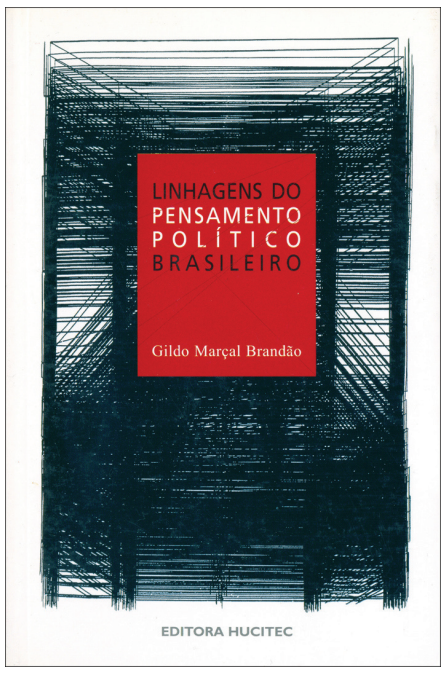

BRANDÃO, Gildo Marçal. Linhagens do
pensamento político brasileiro. São Paulo:
Hucitec, 2007. 220p.

Uma questão metodológica importante suscitada pelo livro é saber se o pertencimento a uma "família" intelectual constitui um ponto de partida estrutural da análise, ou antes, um problema mais contingente, cujo sentido sendo variável em relação à combinação com outros fatores internos e externos de composição das obras, somente a pesquisa comparativa poderá apontar caso a caso. Nas continuidades traçadas no livro, demonstradas especialmente no caso do "idealismo orgânico", as duas alternativas convivem em tensão. Afinal, apesar de algumas linhagens terem se tornado mais cristalizadas, como em qualquer família, também no caso da tradição intelectual brasileira, como bem lembra o autor, por vezes "os mais próximos são os mais distantes, e ninguém pode impedir que um Montecchio se apaixone por uma Capuleto" (p. 39). Nesse sentido, um dos aspectos mais produtivos da proposta é justamente o de, ora perseguindo desenvolvimentos internos ora cruzando diferentes linha- 
gens, surpreender afinidades eletivas e escolhas pragmáticas onde elas não são evidentes, esperadas, intencionais - seja em termos cognitivos ou normativos.

Resta observar se faz sentido - e qual é ele - dedicar-se às tarefas de pesquisas propostas em Linhagens do pensamento politico brasileiro. Persuasivas respostas à questão são desenvolvidas nos três capítulos que compõem a segunda parte do livro, "Teoria política a partir da periferia”. Numa dimensão, parafraseando a justificativa de Antonio Candido quanto à investigação da formação da literatura brasileira, Brandão lembra que tal qual essa, embora galho secundário de um arbusto de segunda, pobre quando comparada às grandes etc., sendo ele que nos exprime se não nos dedicarmos ao pensamento político-social brasileiro ninguém mais, evidentemente, o fará por nós. Noutra, a resposta de Brandão desenvolve a sugestão segundo a qual, como idéias são forças sociopolíticas, as formulações do pensamento e das ciências sociais não são meras descrições externas, mas também influenciam a modelagem das práticas e das próprias instituições, operando ainda como um repertório a que diferentes atores sociais podem recorrer para buscar motivação, perspectiva e argumentos em suas contendas. Daí que, ultrapassando a definição minimalista de política centrada exclusivamente em seus aspectos institucionais, reconstruir as linhagens do pensamento político-social brasileiro e estabelecer relações entre elas e as nossas formas atuais de pensar acabe se revelando também uma condição do esclarecimento e redefinição das estratégias contemporâneas de atuação política.

Perscrutando respostas particulares e muitas vezes descontínuas a problemas gerais, Linhagens do pensamento político brasileiro logra, enfim, reconstituir um processo de acumulação intelectual estruturado e de longa duração por dentro da tradição brasileira. Crucial para tanto, é o entendimento de Brandão de que, apesar das mudanças ocorridas na sociedade brasileira, a estrutura básica sobre a qual nossos autores do passado refletiram e nós prosseguimos desafiados a refletir não foi exatamente alterada substantivamente do ponto de vista social e político e nem mesmo esgotada em termos intelectuais. Ou seja, a inteligibilidade das continuidades intelectuais encontrar-se-ia no próprio processo social, ele mesmo pouco marcado por rupturas. É que o passado, como o livro demonstra, talvez, só venha a estar "plenamente elaborado", de fato, quando "estiverem eliminadas as causas do que passou", para falar com Adorno (1995, p.49). Por isso, a pesquisa do pensamento político-social pode, em meio ao labirinto da especialização acadêmica contemporânea, nos dar uma visão mais integrada e consistente da dimensão de processo que o nosso presente ainda oculta. Aqui justamente, ao lado das contribuições específicas à área de pesquisa na qual se inscreve, o interesse mais amplo de $\mathrm{Li}$ nhagens do pensamento político brasileiro para as ciências sociais.

\section{Nota}

1 Adapto aqui a expressão utilizada por Gabriel Cohn (2003).

\section{Referências bibliográficas}

ADORNO, T. W. O que significa elaborar o passado. In: Educação e emancipação. São Paulo: Paz e Terra, 1995. 
ASSIS, J. M. de. A nova geração. In:

Obra completa. Rio de Janeiro: Aguilar, 1962.

COHN, G. Fine differences: from Simmel to Luhmann. Brazilian Review of Social Sciences, São Paulo, Anpocs, v.2, 2003.

SCHWARZ, R. Nacional por subtração. In: _. Que horas são? Ensaios. São Paulo: Cia. das Letras, 1987.

André Botelho é professor do Departamento de Sociologia da Universidade Federal do Rio de Janeiro (UFRJ) e pesquisador do Conselho Nacional de Desenvolvimento Científico e Tecnológico (CNPq). @ - andrebotelho@digirotas.com.br 